\title{
Dental pulp cells provide neurotrophic support for dopaminergic neurons and differentiate into neurons in vitro; implications for tissue engineering and repair in the nervous system
}

\author{
Irina V. Nosrat, ${ }^{1 *}$ Christopher A. Smith, ${ }^{1 *}$ Patrick Mullally, ${ }^{1}$ Lars Olson ${ }^{2}$ and Christopher A. Nosrat ${ }^{1}$ \\ ${ }^{1}$ Laboratory of Oral Neurobiology, Department of Biologic and Materials Sciences, Room 3218, School of Dentistry, University of \\ Michigan, Ann Arbor, MI 48109-1078, USA \\ ${ }^{2}$ Department of Neuroscience, Karolinska Institutet, Stockholm, Sweden
}

Keywords: BDNF, dopamine, GDNF, neurotrophic factors, NGF, tooth innervation

\begin{abstract}
Glial cell line-derived neurotrophic factor (GDNF) mRNA is highly expressed by dental pulp cells (DPCs) prior to the initiation of dental pulp innervation. We show that radioactively labelled exogenous GDNF is retrogradely transported from neonatal teeth and vibrissae to the trigeminal neurons, indicating that GDNF acts as a classical neurotrophic factor in the trigeminal system. We also show that DPCs from both rats and humans produce nerve growth factor (NGF), brain-derived neurotrophic factor (BDNF) and GDNF mRNAs in vitro, promote the survival and phenotypic characteristics of embryonic dopaminergic (DA) neurons and protect DA neurons against the neurotoxin 6-hydroxy-dopamine (6-OHDA) in vitro. By using inhibitory antibodies to NGF, BDNF and GDNF, we show that the promotion of DA neuron survival relates to the production and release of neurotrophic proteins by DPCs in vitro. We suggest that in vivo production of neurotrophic factors by DPCs play roles in tooth innervation. However, continued production of neurotrophic factors by the DPCs might have wider implications. We propose that the dental pulp is a viable source of easily attainable cells with possible potential for development of autologous cell transplantation therapies. We also show that a population of neural crest-derived dental pulp cells acquire clear neuronal morphology and protein expression profile in vitro, indicating the presence of a cell population in the dental pulp with neuronal differentiation capacity that might provide additional benefits when grafted into the CNS.
\end{abstract}

\section{Introduction}

The neural crest gives rise to a wide range of tissues in the craniofacial region. One such tissue is the dental pulp. The timing of dental pulp innervation coincides with up-regulation of neurotrophic factor expression by dental pulp cells (DPCs). Nerve growth factor (NGF), brain-derived neurotrophic factor (BDNF) and glial cell line-derived neurotrophic factor (GDNF) mRNA transcripts are highly up-regulated in the dental pulp (Nosrat et al., 1996; Luukko et al., 1997a; Luukko et al., 1997b; Nosrat et al., 1997a; 1998). NGF has been shown to play important roles in tooth innervation (Qian \& Naftel, 1994, 1996) and both NGF- and NGF-receptor TrkA-knockout mice (Byers et al., 1997; Matsuo et al., 2001) exhibit severe deficits in tooth innervation. However, the roles of GDNF in tooth innervation are not clear. While GDNF most probably acts as a target-derived neurotrophic factor for substantia nigra dopaminergic (DA) neurons (Tomac et al., 1995b; Ai et al., 2003), a similar role for GDNF in the trigeminal system requires documentation of specific transport of GDNF from the sites of synthesis in the target fields to the nerve cell. Two such target fields in the trigeminal system that have been shown to synthesize GDNF are developing teeth and vibrissae (Nosrat et al., 1996; 1998).

Correspondence: Dr Christopher Nosrat, as above.

E-mail: nosrat@umich.edu

*I.V.N. and C.A.S. contributed equally to this work.

Received 1 January 2004, revised 11 February 2004, accepted 12 February 2004
The same neurotrophic factors that are produced by the DPCs have been shown to have crucial influence over neurons of the central nervous system (CNS), such as motoneurons or DA neurons of the substantia nigra (Hefti, 1986; Williams et al., 1986; Oppenheim et al., 1992; 1995; Sendtner et al., 1992; Yan et al., 1992; Henderson et al., 1994; Tomac et al., 1995a; Gash et al., 1996). We have shown that DPCs promote the survival of two different classes of neurons, sensory neurons of the trigeminal ganglion and motoneurons of the spinal cord, by providing them with neurotrophic support (Nosrat et al., 2001). Grafting DPCs also promotes the survival of injured motoneurons in an animal model of spinal cord injury (Nosrat et al., 2001). Here, we aimed to evaluate whether DPCs would promote the survival of DA neurons.

It has recently been shown that the dental pulp contains a population of multipotent stem cells with the capacity to differentiate into several different cell lineages in vitro and in vivo, including glial and nerve cells (Gronthos et al., 2000; 2002). Strict criteria must be met to recognize such cells as neurons. These criteria include morphological analysis, presence of specific neuronal markers, and assessment of electrophysiological properties. Adult neuronal stem cells may provide new approaches for an autologous treatment of disease and tissue repair in the nervous system.

In the present study, we show that GDNF is retrogradely transported to the trigeminal neuron cell bodies from vibrissae and teeth. We also demonstrate that DPCs promote the survival and the dopaminergic phenotype of DA neurons, and protect them against the neurotoxin 
6-hydroxydopamine in vitro. In addition, we show that cells from the dental pulp acquire neuronal morphology in vitro.

\section{Materials and methods}

\section{Retrograde transport of ${ }^{125} /$-GDNF}

Human GDNF protein (a kind gift from Amgen, Thousand Oaks, CA, USA) was labelled with Iodine-125 using Bolton \& Hunter reagent (Amersham Biosciences, Piscataway, NJ, USA). ${ }^{125}$ I-GDNF had a specific activity of $161 \mu \mathrm{Ci} / \mathrm{nmol}$. Fifty nanograms of labelled GDNF protein in $2 \mu \mathrm{L}$ of PBS solution was used for each injection. ${ }^{125} \mathrm{I}-$ GDNF in 100-fold concentration of cold GDNF was used as control. Postnatal day (P)1, P3 and adult female 250-g Sprague-Dawley rats were used in the experiments. Procedures were approved by the Ethics Committee, Stockholm, Sweden. P1 rats ( $n=6$, two controls) received two injections of ${ }^{125}$ I-GDNF and the control solution subcutaneously in the right side vibrissae. One injection per P1 rat pup $(n=6$, two controls) was also made in the area of the inferior alveolar nerve. ${ }^{125} \mathrm{I}-$ GDNF and the control solution were also injected into the maxillary teeth of $\mathrm{P} 3$ rat pups $(n=6)$. These injections targeted the dental pulp in the maxillary teeth. Mineralized tissues in developing teeth at this stage do not prevent penetrating the dental pulp with the needle, and the needle was progressed into the teeth to reach the pulps. It is, however, possible that solutions might also have leaked into the surrounding dental follicle area and thus to the mechanosensory and somatosensory nerve fibers in the periodontal membrane. Adult rats $(n=6)$ received five injections each of $50 \mathrm{ng}$ of labelled GDNF and the control solution. Animals were anaesthetised with nembutal (200 mg/kg body weight) and killed after $24 \mathrm{~h}$ and perfused with $4 \%$ paraformaldehde in PBS. Cryostat sections (14- $\mu$ m-thick sections) of trigeminal ganglia (and the site of injection) were mounted on gelatin-coated slides. Slides were dehydrated, dried, dipped in photographic emulsion (Kodak NTB-2) and exposed for 5-6weeks at $-20{ }^{\circ}$ C. Slides were subsequently developed (Kodak D19 developer) and counterstained with Cresyl Violet. Slides were evaluated and the number of trigeminal neurons with strong accumulation of silver grains were counted using a Nikon microscope. Counts were performed on every third slide and images recorded (Nikon EXM1200 digital camera).

\section{RNA isolation, cDNA synthesis and RT-PCR}

Sprague-Dawley rats (Charles River, Willmington, MA, USA) were used in all experiments for obtaining rat cells. Procedures were approved by the Institutional Animal User Committee (IAUC) at the University of Michigan. Dental pulp tissue from 6-8-day-old rat pups were used. The reasons for choosing this particular age are discussed elsewhere (Nosrat et al., 2001). Dental pulps were dissected, placed in a sterile Petri dish containing ice-cold Dulbecco's modified Eagle's medium and Ham's F12 nutrients (DMEM/F12), 5\% fetal bovine serum (FBS; Gibco BRL), L-glutamine ( $2 \mathrm{mM})$, penicillin (100 U/mL), streptomycin $(100 \mu \mathrm{g} / \mathrm{mL})$, amphotericin $(2 \mu \mathrm{g} / \mathrm{mL})$ and gentamicin $(50 \mu \mathrm{g} / \mathrm{mL})$. Tissue pieces were mechanically dissociated and washed twice with Earl's balanced salt solution (EBSS) without calcium or magnesium. Tissue fragments were then trypsinized for $20-30 \mathrm{~min}$ with $0.25 \mu \mathrm{g} / \mathrm{mL}$ trypsin, and were further mechanically dissociated with fire-polished Pasteur pipettes, and seeded $\left(\approx 10^{5}\right)$ on poly-D-lysine $(100 \mu \mathrm{g} / \mathrm{mL})$-treated flasks and glass chamber slides (Falkon). DPCs that had been subcultured at least twice were used in these experiments. Cultures were kept in a humidified incubator at $37{ }^{\circ} \mathrm{C}$ with $95 \%$ air and $5 \% \mathrm{CO}_{2}$, and the medium was changed every 2 days.
Human DPCs were obtained from patients undergoing routine extractions of third molars (18-30years of age, both males and females) in the clinics of the Department of Oral Surgery and Medicine, University of Michigan, Ann Arbor, Michigan, USA. The use of human tissue was approved by the human Institutional Review Board at the University of Michigan. A relatively large amount of tissue is obtained from a single extracted tooth. Dental pulps were dissected from extracted teeth and placed in culture medium (as above but containing $20 \%$ FBS) on ice. Human dental pulp tissue was mechanically minced and plated onto poly-D-lysine $(100 \mu \mathrm{g} / \mathrm{mL})$ treated flasks. Confluent cultures were subcultured by trypsinization. Cells used in these experiments had been passaged at least three times.

Human and rat dental pulp cell total RNA was prepared using Trizol reagent (Invitrogen) according to the manufacturer's recommendations. Total RNA was treated with DNase (RQ1 DNase, Promega, $1 \mathrm{~h}$ ) prior to reverse transcription. First and second strand cDNA synthesis was performed using the SuperScript double-stranded cDNA synthesis system (Invitrogen). Five hundred nanograms of both human and rat dental pulp cell cDNAs were used in each PCR reaction and no cDNA was added to the control PCR reactions. The rat primer pairs were rat NGF: sense 5'-ACATCAAGGGCAAGGAGGTGAC-3, antisense 5'TGACAAAGGTGTGAGTCGTGGTG-3', from GenBank Accession number XM_227525; rat BDNF: sense 5'-GGTCACAGCGGCAGATAAAAAGAC- ${ }^{\prime}$, antisense $5^{\prime}$-TTGGGTAGTTCGGCATTGCGAG$3^{\prime}$, from GenBank Accession number NM_012513; and rat GDNF: sense $5^{\prime}$-GCTACGAAACCAAGGAGGAACTG-3', antisense $5^{\prime}$ TGGAGCCAGGGTCAGATACATC- ${ }^{\prime}$, from GenBank Accession number NM_019139.

Human NGF: sense 5'-ATACAGGCGGAACCACACTCAG-3', antisense 5'-GTCCACAGTAATGTTGCGGGTC-3', from GenBank Accession number NM_002506; human BDNF: sense 5'-CACCAGATAAACAAATGGCAGTGC-3', antisense 5'-CGACAGGTCATCATCAAAGGCG-3' ${ }^{\prime}$, from GenBank Accession number NM_000514; and human GDNF: sense 5'-AGAGGCTTGACATCATTGGCTG-3', antisense 5'-CAAAGGCACTTGACTACTGAGCATC-3' ${ }^{\prime}$, from GenBank Accession number NM_170732. The reactions were preincubated in a PCR Mastercycler Gradient (Eppendorf) at $94{ }^{\circ} \mathrm{C}$ for $2 \mathrm{~min}$ and then cycled 30 times at $94{ }^{\circ} \mathrm{C}(20 \mathrm{~s}), 52^{\circ} \mathrm{C}(20 \mathrm{~s})$ and $68^{\circ} \mathrm{C}(30 \mathrm{~s})$ followed by a final 4-min extension at $68^{\circ} \mathrm{C}$. All PCR products were sequenced at the University of Michigan DNA sequencing core to verify that correct DNA fragments had been amplified.

\section{Ventral mesencephalon (VM) dissection and coculture procedure}

Timed pregnant Sprague-Dawley rats were obtained from Charles River breeders. The day on which the rats are sperm-positive (a detectable sperm plug) is designated the first day of gestation (E1). To accurately estimate the age of the embryos, crown-rump length was also measured (Olson et al., 1983; Dunnett \& Björklund, 1992). Fetuses were removed from pregnant females that had been asphyxiated with $\mathrm{CO}_{2}$. Fetuses were decapitated and brains were dissected. Using a lateral approach, the ventral mesencephalon was located and dissected (Dunnett \& Björklund, 1992). VM tissue was then placed in a Petri dish containing ice-cold DMEM/F12 (Invitrogen), 5\% FBS, L-glutamine (2 mM), penicillin (100 U/mL), streptomycin $(100 \mu \mathrm{g} / \mathrm{mL})$, amphotericin $(2 \mathrm{mg} / \mathrm{mL})$ and gentamicin $(50 \mu \mathrm{g} /$ $\mathrm{mL}$ ). Tissue pieces were mechanically dissociated and washed twice with Hank's balanced salt solution (HBSS) without calcium or magnesium. Tissue fragments were then trypsinized for $10 \mathrm{~min}$ with $0.1 \mu \mathrm{g} / \mathrm{mL}$ trypsin and were further mechanically dissociated with fire-polished Pasteur pipettes. The cells were seeded on poly-D-lysine $(100 \mu \mathrm{g} / \mathrm{mL})$-treated flasks or 12 -well plates (Falkon) alone (control) 
and/or with previously cultured DPCs as described above. Cultures were kept in a humidified incubator at $37{ }^{\circ} \mathrm{C}$ with $95 \%$ air and $5 \% \mathrm{CO}_{2}$. To prevent direct contact between DPCs and cells from the VM, tissue culture inserts with a pore size of $1 \mu \mathrm{m}$ (Becton Dickinson, Franklin Lakes, NJ, USA) were used. In these experiments, DPCs were cultured in the inserts until confluency. Dissociated VM cells were then seeded into the 12-well plates that contained inserts with cultured DPCs. At different time intervals, VM cells were fixed with 4\% PFA in PBS, washed several times with PBS, blocked with a solution containing 5\% heat-inactivated normal goat serum (NGS), 5\% heat-inactivated normal horse serum (NHS), 5\% bovine serum albumin (BSA) and $0.3 \%$ Triton-X in PBS. Cells were then incubated with antibodies to tyrosine hydroxylase (TH; Pel-Freez) in blocking solution overnight at $4{ }^{\circ} \mathrm{C}$. Cells were subsequently washed with PBS and processed (VectaStain ABC Elite system; according to manufacturer's recommendations), and visualized (diaminobenzidine substrate kit; Vector Laboratories, Burlingame, CA, USA). Cells with clear labelling in each cell culture well were counted. The software package for the digital camera (Spot, Diagnostic Instruments, Sterling Heights, MI, USA) was used to measure cell size and the length of longest primary neurite on representative TH-positive cells. At least 10 cells were selected for each condition. However, this was not possible for VM cultures beyond 7 days, due to the scarcity of TH-positive cells present. The number of primary neurites was also counted on TH-positive cells. ANOVA followed by Student-Newman-Kuels multiple comparisons test (Instat 2.03, Graph Pad Software, San Diego, CA, USA) was used. ${ }^{* * *} P<0.001,{ }^{* *} P<0.01$, and ${ }^{*} P<0.05$. For the inhibitory antibody blocking studies, antibodies to NGF (R\&D Systems), BDNF (Promega) and GDNF (R\&D Systems) were used in concentrations recommended by the manufacturer. Cells were fixed 4 days after antibodies were added to the culture medium and visualized as described above. BSA ( $1 \mu \mathrm{g} / \mathrm{mL}$ culture medium) was added to the control cultures.

\section{Culture treatments with 6-OHDA and cell counts}

6-OHDA (Sigma) was dissolved in water containing $0.1 \%$ ascorbic acid (Sigma). DPCs and cells from E14 ventral mesencephalon (which contain DA neurons) were plated onto 12 -well plates for $24 \mathrm{~h}$. After $24 \mathrm{~h}$ in vitro, cocultures of dental pulp and VM cells, and VM cells alone were given fresh culture medium (control) or culture medium containing 6-OHDA $(5 \mu \mathrm{M}$ or $10 \mu \mathrm{M})$. The toxicity of 6-OHDA and possible DA neuron protection by DPCs were determined by counting TH-positive cells as described above. TH-positive cells were counted using an inverted microscope at 10× (Nikon Eclipse TE300). Experiments were performed with different conditions in triplicate at three different time points. ANOVA followed by Tukey's HD post hoc test (Instat 2.03, Graph Pad Software, San Diego, USA) was used.

\section{Immunohistochemistry}

Human and rat DPCs and rat VM cells were fixed in $4 \%$ paraformaldehyde in PBS (PBS, 0.5 M NaCl, 0.01 M phosphate buffer, pH 7.2-7.4) for 30-60 min, washed with PBS five times for $6 \mathrm{~min}$, preincubated in a blocking solution of PBS containing 5\% normal goat serum and/or normal horse serum and $5 \%$ bovine serum albumin and $0.3 \%$ Triton $\mathrm{X}-100$ for $1 \mathrm{~h}$, followed by overnight incubation with the different antisera in blocking solution. Antibodies against $\beta$-III tubulin (Covance), protein gene product 9.5 (PGP; Biogenesis Ltd., UK), growthassociated protein 43 (GAP-43; Chemicon International, Inc., Temecula, CA, USA), and glial fibrillary acidic protein (GFAP; Sigma), TH (Pel-Freez), S-100 and nestin (Chemicon International, Inc., Temecula, CA, USA) were used. Chamber slides or flasks were subsequently washed four times in PBS, incubated for $1 \mathrm{~h}$ with biotinylated secondary antibodies followed by an avidin-biotin complex (Vectastain ABC Elite; Vector Laboratories, CA, USA). The peroxidase activity was visualized with diaminobenzidine (DAB) peroxidase substrate and Vector VIP kit (Vector Laboratories).

\section{Cell nuclei labelling with bisbenzimide and striatal grafts of DPCs}

In order to detect DPCs after being grafted into CNS in rats, DPCs were incubated for $30 \mathrm{~min}$ at $37^{\circ} \mathrm{C}$ in complete darkness with a culture medium containing $10 \mu \mathrm{g} / \mathrm{mL}$ bisbenzimide (Sigma). The cells were rinsed many times with HBSS and twice with culture medium and kept overnight in an incubator. The following day, cells were washed several times, trypsinized and washed at least five times with HBSS and twice in culture medium, resuspended and kept in regular culture medium in a concentration of $2 \times 10^{5}$ cells $/ \mu \mathrm{L}$ prior to grafting. We have successfully used this technique to label cells in culture or cells that have been grafted. Bisbenzimide is not toxic at this concentration as evaluated in cultures that have been kept for several months. The cells also retain their labelling for extended periods of time in vivo. We are aware of the phenomenon of lateral diffusion of the dye but find that, using multiple stringent washes, excess bisbenzimide nuclear stain is rinsed off and labelling of adherent cells does not occur. Another important issue with regard to this labelling is that only cells with dense labelling in the nuclei are evaluated as positive. Anaesthetized (Nembutal, $30 \mathrm{mg} / \mathrm{kg}$ weight) adult female Sprague-Dawley rats received stereotactic (AP 0.0, ML 3.4, DV $5.0 \mathrm{~mm}$ ) injections of bisbenzimidelabelled DPCs $\left(5 \mu \mathrm{L}\right.$ of $2 \times 10^{5}$ cells $\left./ \mu \mathrm{L}\right)$ into right striata $(n=6)$. Two animals received DPCs that had been fixed in 4\% PFA in PBS and washed five times prior to grafting. Rats were killed with an overdose of nembutal ( $200 \mathrm{mg} / \mathrm{kg}$ body weight) and perfused with 4\% PFA in PBS; brains were dissected and postfixed in the same medium for $2 \mathrm{~h}$, cryopreserved in $10 \%$ sucrose in PBS, cryosectioned (14 $\mu \mathrm{m}$ thick) and mounted onto gelatin-coated slides. Slides were washed three times in PBS and mounted with coverslips with $1: 1$ glycerol-PBS. Bisbenzimide labelling was visualized with a UV filter.

\section{Results}

\section{GDNF was retrogradely transported to trigeminal neurons}

To investigate the possible neurotrophic role of GDNF in the trigeminal system, ${ }^{125}$ I-GDNF was injected into whisker pads of neonatal and adult rats, into the developing maxillary teeth and into the area of the inferior alveolar nerve that supplies the innervation of the mandibular teeth. ${ }^{125}$ I-GDNF coinjected with a 100-fold excess of nonlabelled GDNF served as control. No marked inflammation was seen in the injection sites in the vibrissae and moderate amounts of silver grains were located close to the injection sites (not shown). Strong accumulation of silver grains above trigeminal neurons indicated that ${ }^{125} \mathrm{I}$-GDNF was retrogradely transported from the whisker pads in both neonatal (Fig. 1A-C) and adult animals, and from neonatal inferior alveolar nerve and teeth (Fig. 1D-F). There was a larger number of neurons labelled in neonatal trigeminal ganglia than in the adults (Fig. 1G). No labelling was seen in control ganglia, indicating that nonlabelled GDNF selectively and successfully competes with ${ }^{125}$ I-GDNF. Contralateral trigeminal ganglia did not contain any labelling. It has been shown that the receptor components for GDNF, GFR (GDNF family receptor)- $\alpha$ and Ret mRNA are expressed in the trigeminal ganglion and trigeminal nuclei in the brain stem (Nosrat et al., 1997b). These findings therefore suggest that GDNF may exert a classical neurotrophic effect in the trigeminal system and participate in tooth innervation. 

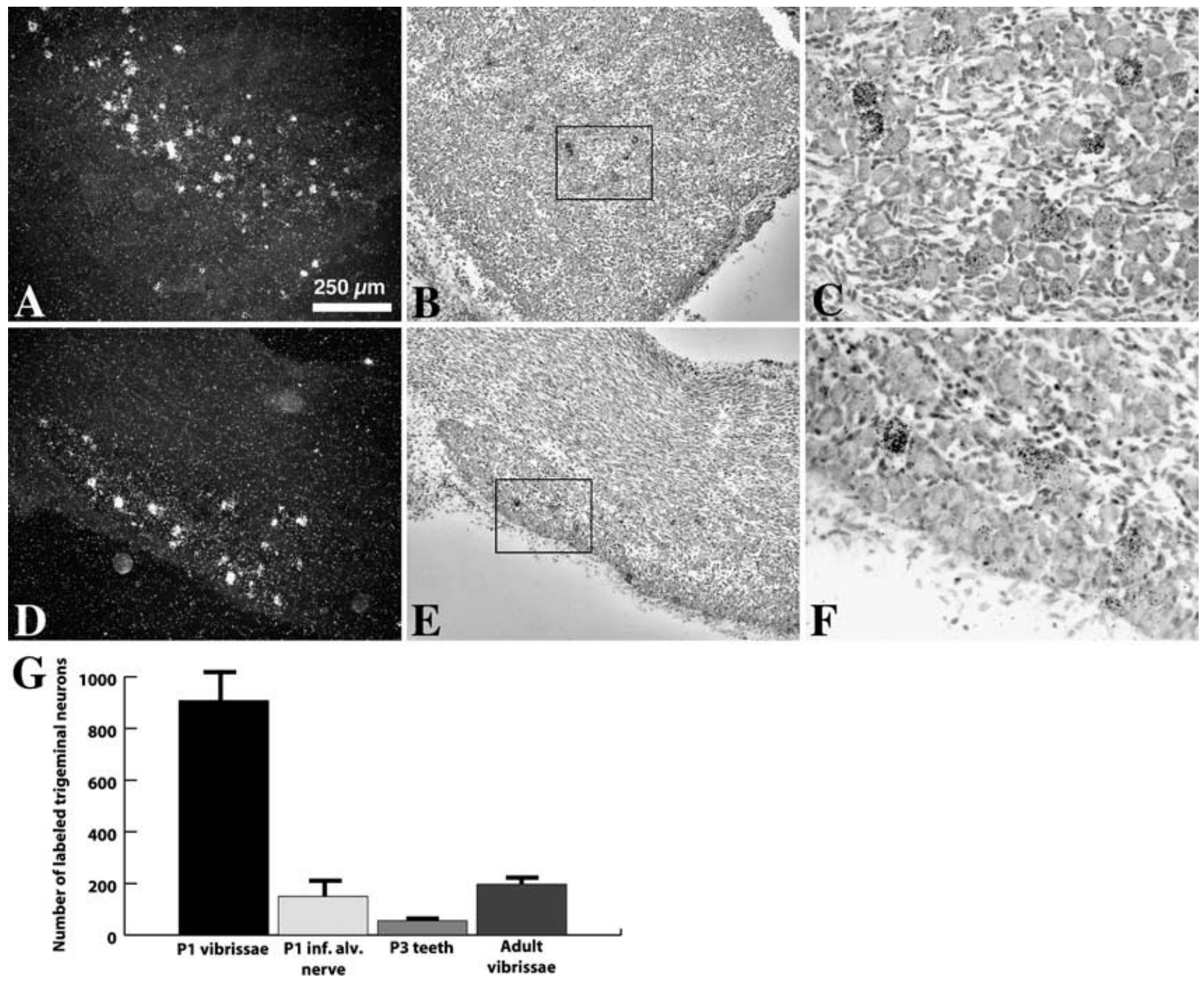

FIG. 1. GDNF is retrogradely transported from (A-C) vibrissae and (D-F) teeth to trigeminal neurons. (A and B) Dark- and bright-field photomicrographs of trigeminal neurons. ${ }^{125}$ I-GDNF labelling is seen in trigeminal neurons indicating retrograde transport of GDNF from injection sites in whisker pads of 1-day-old rat pups. (C) Higher magnification of the boxed area in B. (D and E) Dark- and bright-field photomicrographs of trigeminal neurons. ${ }^{125} \mathrm{I}-\mathrm{GDNF}$ labelling is seen in trigeminal neurons indicating retrograde transport of GDNF from injection sites in teeth of 3-day-old rat pups. (F) Higher magnification of the boxed area in E. (G) Number of labelled neurons in trigeminal ganglion. ${ }^{125}$ I-GDNF was injected subcutaneously into the whisker pads (P1 and adult rats), into the area of the inferior alveolar nerve (inf. alv. nerve; P1 rats) and into the developing dental pulp (P3 rats). No labelling was seen in the contralateral trigeminal ganglion, or when

${ }^{125}$ I-GDNF was injected together with a 100-fold excess of nonlabelled GDNF. Scale bar, $250 \mu \mathrm{m}$ (in A for A, B, D and E).

\section{Dental pulp cells produced neurotrophic factors in vitro}

NGF, BDNF and GDNF transcripts are found in vivo in the rat dental pulp at the time of the onset of dental pulp innervation (Nosrat et al., 1998). We have also shown that developing human teeth express neurotrophic factor mRNAs (Nosrat et al., 2002b). In order to study

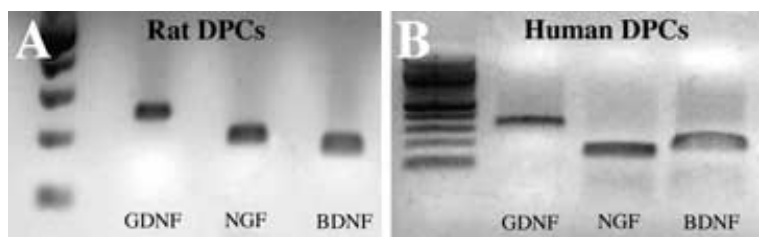

FIG. 2. (A) Rat and (B) human DPCs express mRNAs for GDNF, NGF, and BDNF in culture. Lane 1 is 100 bp DNA ladder. whether these factors are expressed by DPCs in vitro, we used RT-PCR on total RNA isolated from both rat and human DPCs. Cultures were maintained from several weeks to months prior to RNA isolation. NGF, BDNF and GDNF mRNA transcripts were expressed by both rat and human DPCs in culture (Fig. 2A and B). The PCR fragments were sequenced and verified. Control reactions were also negative. These results suggest that cultured DPCs have the ability to produce neurotrophic factors.

\section{Dental pulp-derived neurotrophic factors promoted the survival of embryonic DA neurons}

We tested the hypothesis that DPCs would produce neurotrophic factors in vitro and promote the survival of embryonic DA neurons by coculturing DPCs with embryonic DA neurons. DPCs significantly promoted the survival of embryonic TH-positive neurons for up to 


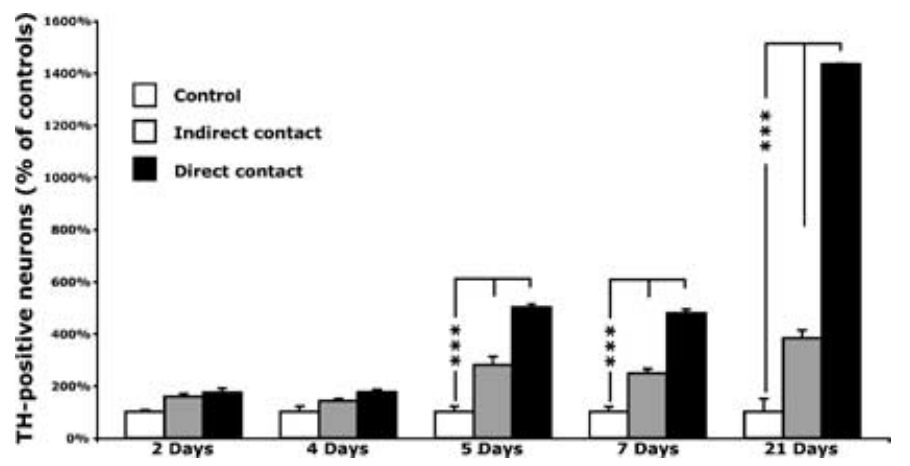

FIG. 3. DPCs promote the survival of embryonic DA neurons in vitro. TH immunoreactivity was used to visualize DA neurons. The number of THpositive neurons in each experimental group is given as a percentage of the number of TH-positive neurons under the control condition. DA neurons were cocultured either directly or indirectly (using porous cell culture inserts) for up to 21 days. When DPCs were in close proximity to DA neurons and when they were separated and located at a distance of several millimeters from each other, they increased the rate of surviving DA neurons in vitro. The results from the indirect coculture procedure indicate that soluble molecules are released by the DPCs in culture and that they have a survival-promoting effect on DA neurons. The experiments were performed in triplicate and at three different time points. ${ }^{* * *} P<0.001$ (ANOVA followed by Newmann-Keuls post hoc test). The experiments were performed in triplicate at three different time points.

3 weeks in culture (the latest time-point studied) compared to the control condition (Fig. 3). When DPCs were cocultured directly with embryonic DA neurons, they promoted the survival of DA neurons by $\approx 500 \%$ after 7 days and $1400 \%$ after 21 days compared to controls (Fig.3). In order to determine whether the DPC survival-promoting effect was due to production and release of soluble molecules, cultures were separated from each other. DPCs were cultured in cell culture inserts and DA neurons located in the bottom of 12-well plates. The inserts contained a porous membrane $(1 \mu \mathrm{m})$ that allowed for exchange of soluble molecules but separated the cell culture compartments effectively from each other and prevented cells from different tissue sources from coming into direct contact. DPCs were separated from DA neurons by a relatively large biological distance (a few mm). Only a few TH-positive cells were found in control 21-day cultures. Soluble factors released by DPCs significantly promoted the survival of DA neurons in cultures.

To determine the nature of the soluble trophic factors released by DPCs, inhibitory antibodies to selected neurotrophic factors were added to the culture medium. Cells of the ventral mesencephalon (VM) were plated directly on confluent cultures of DPCs. The same starting amounts of VM cells were added to each well. One hour later, the antibodies were added to the culture medium. Cells were fixed after 4 days in culture and TH-positive neurons were counted. NGF, BDNF and GDNF antibodies all decreased the number of surviving DA neurons cocultured with DPCs compared to when no inhibitory antibodies were added to the cultures (Fig. 4). This demonstrated that dental pulp-derived neurotrophic factors are indeed responsible for promoting the survival of embryonic DA neurons in vitro. A larger number of DA neurons survived when anti-NGF antibodies were added to the cultures alone than when anti-BDNF or anti-GDNF or all three antibodies were added to the cocultures. Addition of all three antibodies did not totally prevent the survival-promoting effects of DPCs, presumably in part due to the production of several additional potent neurotrophic factors by DPCs (unpublished results). For instance, members of he transforming growth factor- $\beta$ family are essential for induction and maintenance of ventral mesencephalic dopaminergic neurons in vitro and in vivo (Farkas et al., 2003).

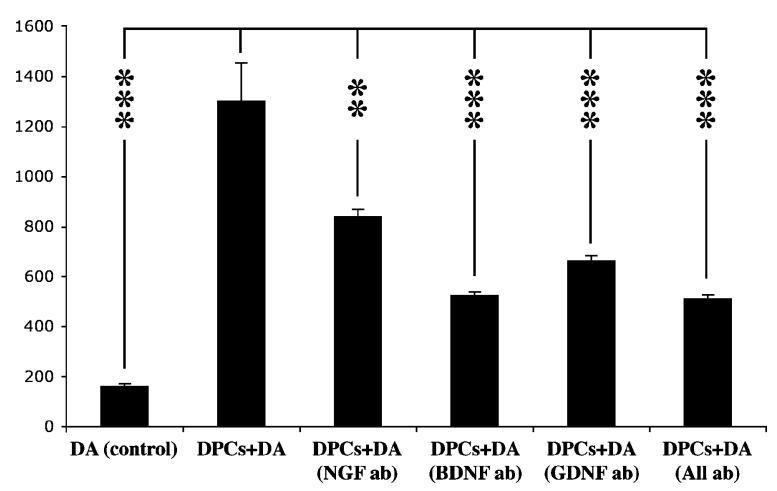

FIG. 4. Inhibitory antibodies to NGF, BDNF and GDNF were used to examine the nature of the soluble factors that are released by DPCs. All antibodies decreased the number of surviving DA neurons that were cocultured with DPCs compared to controls. A larger number of DA neurons survived when anti-NGF antibodies were added to the cultures alone than when anti-BDNF or antiGDNF or all three antibodies were added to the cocultures (ANOVA followed by Bonferroni's post hoc test). The number of TH-positive neurons is given on the $y$-axis. There was also a larger number of TH-positive neurons surviving in the coculture experiments when all of the inhibitory antibodies were added than when cells from the ventral mesencephalon (DA control) were cultured alone. DPCs express transcripts for several additional potent neurotrophic factors (our unpublished observations) that have been shown to promote the survival of DA neurons in culture. The experiments were performed in triplicate at three different time points.

Interestingly, DPCs had a wider biological effect on embryonic DA neurons than the mere promotion of survival. DA neurons that were cocultured with DPCs thrived well in the culture system (Fig. 5B, D and F) compared to the control DA neurons (Fig. 5A, C and E). This was exemplified by a larger soma size, a larger number of primary neurites and an increased length of the primary neurites, indicating that DPCs promoted the dopaminergic phenotype of DA neurons in vitro (Fig. 5G-I). There were only a few TH-positive cells present in 21-day control cultures while many were present in DPC-DA neuron cocultures. Twenty-one-day TH-positive neurons in the coculture experiments had several primary neurites $[2.96 \pm 0.20(\mathrm{SEM}), n=30]$ and the longest primary neurite was relatively similar to 7-day cultures ( $141 \pm 17 \mu \mathrm{m}, n=28$ at 21 days, and $155 \pm 12 \mu \mathrm{m}$ at 7 days). Due to the massive loss of $\mathrm{TH}$-positive cells under control conditions at 21 days, statistical analysis regarding phenotypes of TH-positive cells was not performed.

\section{DPCs protected DA neurons against 6-OHDA}

In order to study the possible neuroprotective effect of DPCs on DA neurons, we used a model system developed by Carrasco \& Werner (2002). VM cells were cocultured with DPCs and 6-OHDA was added to the culture medium. VM cells were cultured alone without DPCs as a control and two different concentrations $(5 \mu \mathrm{M}$ and $10 \mu \mathrm{M})$ of 6-OHDA were used to evaluate the dose-dependency of 6-OHDA toxicity. 6-OHDA did have the predicted detrimental effect on neurons in all cultures exposed to the toxin for $24 \mathrm{~h}$ (Fig. 6). However, in the presence of DPCs, cocultures of DA neurons exposed to 6-OHDA survived in much greater numbers than those without DPCs (Fig. 6). Thus, DPCs exerted a protective effect on DA neurons against 6-OHDA in this in vitro system.

\section{Cultured dental pulp cells contained cells with neuronal phenotype}

Cultured DPCs constitute a heterogeneous population that includes stem cells (Gronthos et al., 2000). Our results demonstrate that both rat and human DPCs can differentiate into and maintain a neuronal 

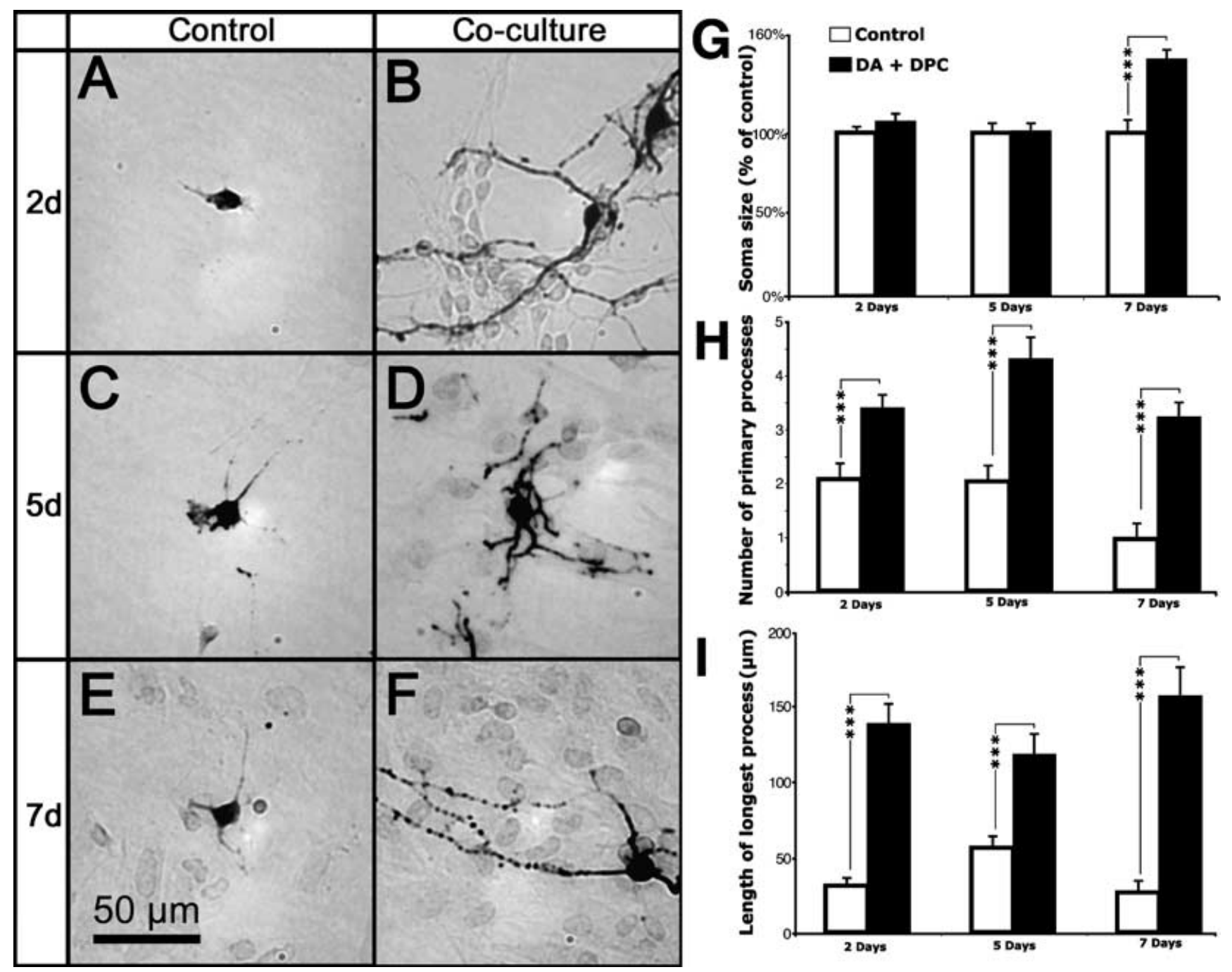

FIG. 5. Dental pulp-derived neurotrophic factors not only promoted the survival of DA neurons, they also promoted the dopaminergic phenotype of DA neurons. (A-F) Examples of such DA neurons. (A, C and E) Without DPCs, DA neurons appear atrophic and do not extend elaborate neurites. (B, D and F) However, DA neurons extend several neurites that contain many varicosities when cocultured with DPCs. (G-I) DA neurons that were cocultured with DPCs had a larger soma size (G, given as a percentage of the number of DA neurons in cocultures compared to VM cells cultured alone), a larger number of primary neurites (H) and longer primary neurites (I) than control DA neurons. (ANOVA followed by Newmann-Keuls post hoc test).

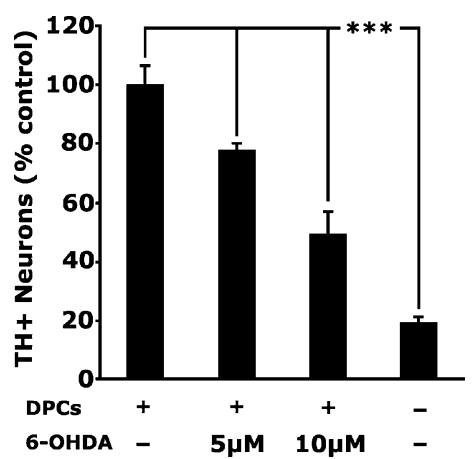

FIG. 6. DPCs protect embryonic DA neurons against 6-OHDA toxicity in vitro. Addition of 6-OHDA to the culture medium killed $80 \%$ of DA neurons in single cultures. DPCs promoted the survival of DA neurons in vitro and protected DA neurons against 6-OHDA in vitro. About $80 \%$ of DA neurons survived despite addition of 6-OHDA $(5 \mu \mathrm{M})$ to the culture medium. TH immunoreactivity was used to visualize DA neurons. DPC neuroprotection is given as a percentage survival of DA neurons in comparison to when no 6-OHDA was added to DADPC cocultures (100\% survival). (ANOVA followed by Bonferroni post hoc test). The experiments were performed in triplicate at three different time points. morphology (Fig. 7A-K). We used different neural markers (PGP 9.5 and $\beta$-III tubulin) to characterize the protein expression patterns in these cells. Our results indicate that dental pulp-derived cells having a neuronal morphology express several neuron-specific markers. PGP 9.5-positive cells with neuronal morphology (i.e. round cell body with at least three primary neurites) constituted $\approx 3-6 \%$ (see Fig. $7 \mathrm{~F}$ ) of the total number of DPCs in primary cultures of dental pulp and would keep this neuronal morphology for extended periods of time (up to 6 months). S-100- and GFAP-positive cells were also observed in dental pulp cell cultures (potentially Schwann or glial cells). Labeled (PGP 9.5- and $\beta$-III tubulin-positive) human DPCs with neuronal morphology were observed in confluent cultures of DPCs (Fig. 7D-K). DPC-derived neurons were not TH-positive under normal culture conditions (not shown).

\section{DPCs survived in a CNS environment}

To evaluate survival of DPCs when grafted into a CNS environment, we grafted DPCs into the caudate nucleus. Labeled DPCs (RamonCueto et al., 1998; Nosrat et al., 2001) were grafted into the right side using a stereotactic frame. Animals were killed after 6 weeks. Cells 

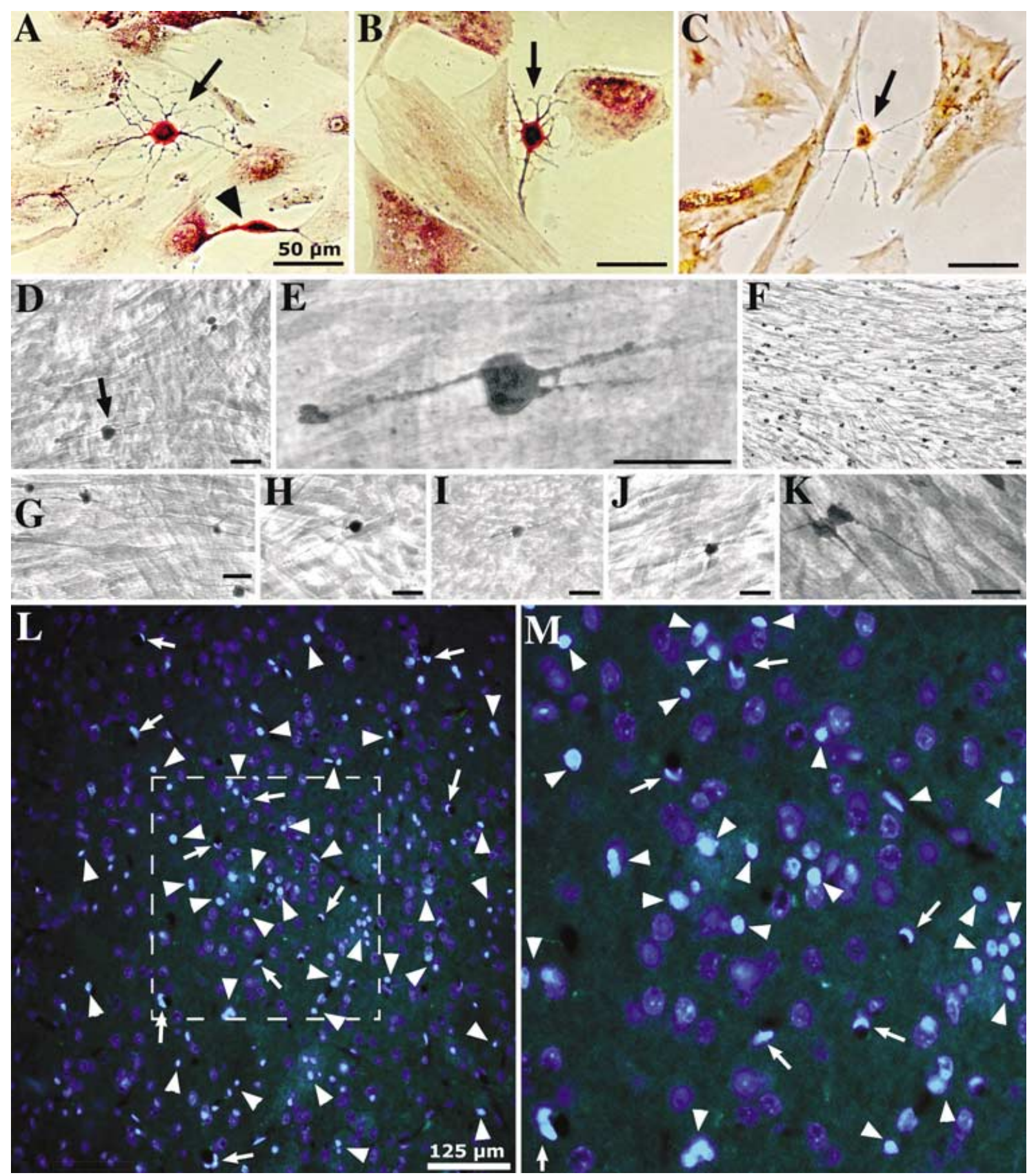

FIG. 7. Some dental pulp cells acquired neuronal morphology in culture. (A-C) Rat and (D-K) human DPCs. Cells had clear neuronal morphology (round soma and several primary processes) and were labelled by neuronal markers (PGP 9.5 and $\beta$-III tubulin). The arrows in A-C indicate multipolar neurons and the arrowhead in A a putative bipolar neuron. Photographs in A and B were taken 5 months after the cultures were established (PGP 9.5). C was photographed after 2 months ( $\beta$-III tubulin). These cells have elaborate processes with terminal bulbs. Also note that the cells demonstrate growth cone morphologies with filopodial extensions. (D-K) Examples of human DPCs stained with neuronal markers (D, E and G-K, PGP 9.5; F, $\beta$-III tubulin). E is a higher magnification of the neuron (arrow) with several primary processes in D. (L-M) Rat DPCs survive for extended periods of time in a CNS microenvironment. DPCs were stereotactically injected into the right striatum. Only cells with strong nuclear labelling were considered positive and are shown with arrows and arrowheads in the figures. Cells spread distinctly into the surrounding striatal tissue. Note that labelled cells appear to be incorporated into surrounding neuropil (arrowheads) and are also found in the lining of blood vessels (arrows).

with strong labelling in the nuclei appeared to survive well in the CNS environment for up to 6 weeks and appeared to have spread over considerable distances within the ipsilateral striatum (Fig. 7L and M, arrows and arrowheads in Fig. 7N) and many were also found lining the blood vessels (arrows). The stringent labelling protocol and extensive washes we used improved this labelling technique. We only evaluated cells with strong nuclear labelling, indicating intact cells. Dead cells are phagocytized by macrophages and microglia and, therefore, diffuse and weak nuclear and cytoplasmic labelling were regarded as nonspecific. DPCs clearly migrated from the injection site in the striatum 
to the surrounding neuropil. These results demonstrate that DPCs can endure the grafting procedure, survive in the CNS environment and migrate from the injection site.

\section{Discussion}

Dental pulp is derived from the neural crest and has been shown to produce a large number of neurotrophic factors during development such as the neurotrophins and GDNF. DPCs continue to express these factors, in culture, for extended periods (Nosrat et al., 1996; 1997a; 2001; Luukko et al., 1997a; 1997b; Lillesaar et al., 2001). Significantly, DPCs have been shown to promote the survival and neurite extension from trigeminal neurons in culture, and to rescue motoneurons in an experimental model of spinal cord injury (Nosrat et al., 2001). Here, we demonstrate that DPCs promote the survival and dopaminergic phenotype of DA neurons in vitro, protect DA neurons against 6-OHDA in vitro and survive when grafted into CNS. Rat and human DPCs also differentiate into cells with neuronal morphology and protein expression profile in vitro.

The dental pulp is the last target tissue in the trigeminal system to become innervated. In rodents, trigeminal nerve fibers reach the developing teeth during early stages of tooth development, but do not innervate the teeth until postnatal stages (Mohamed \& Atkinson, 1983), coinciding with up-regulation of neurotrophic factor expression by DPCs (Nosrat et al., 1998). While all neurotrophins, GDNF and NTN are found in the developing rat (Fried et al., 2000) and human (Nosrat et al., 2002b) teeth, only NGF, BDNF and GDNF mRNAs are expressed in the postnatal dental pulp in rats. Neurotrophic factors appear to have different roles in tooth development and innervation (see Fried et al., 2000). It is noteworthy that they seem to be involved in both tooth development per se and tooth innervation. A good example is NGF. NGF is required for differentiation of cranial neural crest cells into tooth organs, shown by in vitro organ culture studies (Amano et al., 1999). At the same time, tooth innervation is severely reduced or lost in NGF- or TrkA-knockout mice, respectively (Byers et al., 1997; Matsuo et al., 2001), and anti-NGF treatment of neonatal rat pups reduces the amount of sensory axons in the dental pulp (Qian \& Naftel, 1996). NGF is up-regulated after experimental tooth injury (Byers et al., 1992). These indeed indicate different roles for neurotrophic factors in teeth. It has been proposed that GDNF is involved in the regulation of tooth innervation postnatally (Luukko et al., 1997b; Nosrat et al., 1998), based on its patterns of expression, but there is no experimental evidence to support this notion. The present study establishes that GDNF is retrogradely transported from developing teeth to trigeminal neurons, indicating that it might act as a target-derived neurotrophic factor. While gross tooth morphology appears normal in GDNFknockout mice (Granholm et al., 1997; de Vicente et al., 2002), detailed analysis has revealed that both odontoblasts and ameloblasts fail to fully develop and differentiate (de Vicente et al., 2002). Dental pulp innervation could not be assessed in either of these studies because the analysis of GDNF-knockout mice was performed at stages in which the dental pulp had not become innervated. We propose that dental pulp-derived neurotrophic factors play an important role in orchestrating the process of dental pulp innervation.

Exogenous neurotrophic factors are a crucial requirement for in vitro survival of central and peripheral nervous tissues (see Davies, 1994a,b; Rochlin et al., 2000). Because we did not add any exogenous neurotrophic factors to DA neurons in our culture system, DPCs are plausible candidates for neurotrophic support for these neurons in the coculture system. Although CNS glial cells have been shown to produce neurotrophic factors, for instance in response to injury (Widenfalk et al., 2001) or in vitro (Engele et al., 1996), they appear unable to provide enough support for DA neurons in vitro based on the massive loss of DA neurons in the control culture condition. It has been shown that NGF does not influence DA neurons directly; however, inhibitory antibodies to NGF attenuated the number of surviving DA neurons in the antibody-blocking experiment. It is possible that NGF influences DA neurons indirectly by influencing the glial cells that are present in the culture. It has been suggested that the neurotrophic potential of NGF and some other classical neurotrophic factors involves co-operation with other growth factors and cytokines such as members of the transforming growth factor- $\beta$ family (Bottner et al., 2000; Unsicker \& Krieglstein, 2000). It has been shown that NGF regulates proliferation and survival of glial cells (Zhang et al., 2003). Also, the neurotrophic effect of fibroblast growth factors on DA neurons appears to be mediated by mesencephalic glia rather than a direct effect on DA neurons (Engele \& Bohn, 1991). Two sets of experiments in our present work demonstrate that dental pulp cells produce and release soluble factors into the cell culture media. This appears to account for the neurotrophic effect that dental pulp cells have on DA neurons. The first set of experiments identified this by using the coculture arrangement in which the cells were separated by cell-culture inserts. The second set of experiments used inhibitory antibodies to certain neurotrophic factors to identify the possible candidates for this neurotrophic influence on DA neurons. There is some indication in the literature that BDNF and GDNF have additive effects on the survival of DA neurons in culture (for instance see Sautter et al., 1998). The inhibitory antibody assay was repeated many times to examine whether all the three inhibitory antibodies might have additive effects on DA neuron survival in culture. There are several differences between our culture system and that of Sautter et al. (1998). We use dissociated cells (in contrast to free-floating roller tube cultures). Also, they add only BDNF and GNDF proteins into the cultures while, based on our results from screening for neurotrophic factor production by the dental pulp cells, we have found that dental pulp cells produce many such factors in vitro (not shown). Due to the fact that all of these additional factors have been shown to promote the survival of dopaminergic neurons, the antibody-blocking assay identifies a few candidates for the neurotrophic influences exerted by DPCs on DA neurons, but several other factors are possibly involved. The possible presence of additional neurotrophic factors seem to protect DA neurons as seen in both BDNF- and GDNF-knockout animals which do not exhibit any apparent loss of DA neurons (Ernfors et al., 1994; Jones et al., 1994; Pichel et al., 1996). Taken together, our results show that DPCs are responsible for providing neurotrophic support for the sensory neurons, motoneurons and DA neurons. Based on the present results, including the effects of blocking antibodies to NGF, BDNF and GDNF, we propose that dental pulp cells provide a potent cocktail of neurotrophic factors that promote survival and influence axonal morphology of DA neurons in culture.

Cells to be used in cell transplantation therapies in CNS disorders may produce and release neurotransmitters or may produce neurotrophic factors that can counteract degeneration or promote regeneration (see Olson, 1997). Donor availability and the longevity of DA neurons constitute the major limitations for such therapies (see Borlongan et al., 1999; Björklund \& Lindvall, 2000). Generally, long-term functional improvement after cell transplantation therapy is related to the neurotrophic support offered by the grafted tissue rather than mere survival of the grafted cells, including grafted DA neurons (Borlongan et al., 2001; Toledo-Aral et al., 2003). Several different approaches have been utilized to deliver neurotrophic proteins either directly or indirectly into the CNS (see Brundin et al., 2000). Interestingly, sustained release of neurotrophic factors by genetically modified cells has proven to be successful (Arenas \& Persson, 1994; Arenas et al., 
1995). Other cells and tissues that can also produce neurotrophic factors during development include the developing kidney (Karavanov et al., 1995), carotid body (Nosrat et al., 1996) and Sertoli cells (Skinner, 1993). These cells and tissues have all been grafted into the brain and have led to functional recovery in animal models of PD (Sanberg et al., 1997; Espejo et al., 1998; Granholm et al., 1998; Othberg et al., 1998; Rosenthal, 1998; Choi-Lundberg \& Rosenthal, 1999; Luquin et al., 1999). The dental pulp is another source of cells not genetically engineered that produce neurotrophic factors.

Dental pulp contains a population of highly proliferative and clonogenic cells that have the capacity to differentiate into odontoblasts when grafted in vivo under certain conditions and also express markers for other cell lineages such as smooth muscles (Gronthos et al., 2000). The same authors also reported that these dental pulp cells can differentiate into adipocytes, glial or neuronal cells in vitro (Gronthos et al., 2002). Nestin immunoreactivity indicated neuronal cells while GFAP immunoreactivity indicated glial cells. Nestin, however, is found in many other cell types including odontoblasts (Terling et al., 1995; About et al., 2000). Positive immunoreactivity for nestin could indicate an odontoblastic cell lineage in cells derived from the dental pulp. Many criteria must be met in order to classify differentiated dental pulp cells as neurons. In a recent study, Miura et al. (2003) used a plethora of different antibodies to provide strong evidence that stem cells derived from exfoliating human deciduous teeth have the capacity to differentiate into neuronal and glial cells in vitro. When grafted into the brain, they appeared to survive and some cells expressed neuronal markers (Miura et al., 2003). Similarly, we have also grafted dental pulp cells into various regions in the central nervous system (Nosrat et al., 2001; 2002a; present study) and show that DPCs appear to survive for several months in a CNS environment. Our preliminary data also indicate that dental pulp-derived neuronal cells have inward and outward currents under voltage clamp (R.M. Hume and C.A. Nosrat, unpublished observations).

In order to develop successful autologous transplantation therapies for repair and regeneration for the injured nervous system, accessibility of the cells intended for grafting is a very important issue. This type of therapy should preferably use easily accessible tissues from the patient to be treated. If stem cells are to be used, there are several sources already available, such as bone marrow stromal cells (Prockop et al., 2000; Hofstetter et al., 2002), stem cells from the dermis (Toma et al., 2001) and neural crest-derived stem cells (Bixby et al., 2002; Kruger et al., 2002). Dental pulp constitutes an additional interesting source of cells that could be explored for possible autologous transplantation therapy. A significant quantity of cells could be obtained from a single extracted tooth. There are fewer edentulous patients today and teeth are maintained longer in the elderly population as oral health has significantly improved in the industrial world, including the United States (Oral Health in America: A report of the surgeon general, NIH/NIDCR, 2000). This suggests easily accessible cells that could be used as an autograft source in the growing elderly population where PD is more prevalent.

In conclusion, our results indicate that dental pulp-derived neurotrophic factors act as target-derived neurotrophic factors in the trigeminal system. Dental pulp-derived neurotrophic factors promote the survival of DA neurons and provide neuroprotection for DA neurons against 6-OHDA in vitro. Some DPCs also differentiate into cells with neuronal characteristics.

\section{Acknowledgements}

Financial support was obtained from NIH-NIDCR (RO3 DE014455-01A1), Michigan Parkinson's Foundation, The Swedish Research Council (L.O.) and
AMF Sweden (L.O.) We are grateful to Drs Richard Hume and Sean Morrison for discussions and to Drs Paul Krebsbach and Steve Edlund and oral surgery residents at the School of Dentistry, University of Michigan, for assistance with obtaining human dental pulp tissue. We thank Ming Fang and Kyle Kuszpit for technical assistance and cell counts.

\section{Abbreviations}

BDNF, brain-derived neurotrophic factor; CNS, central nervous system; DA, dopaminergic; DPCs, dental pulp cells; GDNF, glial cell line-derived neurotrophic factor; GFAP, glial fibrillary acidic protein; NGF, nerve growth factor; $\mathrm{P}$, postnatal day; PD, Parkinson' disease; PGP, protein gene product 9.5; TH, tyrosine hydroxylase; VM, ventral mesencephalon.

\section{References}

About, I., Laurent-Maquin, D., Lendahl, U. \& Mitsiadis, T.A. (2000) Nestin expression in embryonic and adult human teeth under normal and pathological conditions. Am. J. Pathol., 157, 287-295.

Ai, Y., Markesbery, W., Zhang, Z., Grondin, R., Elseberry, D., Gerhardt, G.A. \& Gash, D.M. (2003) Intraputamenal infusion of GDNF in aged rhesus monkeys: distribution and dopaminergic effects. J. Comp. Neurol., 461, 250-261.

Amano, O., Bringas, P., Takahashi, I., Takahashi, K., Yamane, A., Chai, Y., Nuckolls, G.H., Shum, L. \& Slavkin, H.C. (1999) Nerve growth factor (NGF) supports tooth morphogenesis in mouse first branchial arch explants. Dev. Dyn., 216, 299-310.

Arenas, E. \& Persson, H. (1994) Neurotrophin-3 prevents the death of adult central noradrenergic neurons in vivo. Nature, 367, 368-371.

Arenas, E., Trupp, M., Akerud, P. \& Ibáñez, D. (1995) GDNF prevents degeneration and promotes the phenotype of brain noradrenergic neuros in vivo. Neuron, 15, 1465-1473.

Bixby, S., Kruger, G.M., Mosher, J.T., Joseph, N.M. \& Morrison, S.J. (2002) Cell-intrinsic differences between stem cells from different regions of the peripheral nervous system regulate the generation of neural diversity. Neuron, 35, 643-656.

Björklund, A. \& Lindvall, O. (2000) Cell replacement therapies for central nervous system disorders. Nat. Neurosci., 3, 537-544.

Borlongan, C.V., Sanberg, P.R. \& Freeman, T.B. (1999) Neural transplantation for neurodegenerative disorders. Lancet, 353, SI29-30.

Borlongan, C.V., Zhou, F.C., Hayashi, T., Su, T.P., Hoffer, B.J. \& Wang, Y. (2001) Involvement of GDNF in neuronal protection against 6-OHDAinduced parkinsonism following intracerebral transplantation of fetal kidney tissues in adult rats. Neurobiol. Dis., 8, 636-646.

Bottner, M., Krieglstein, K. \& Unsicker, K. (2000) The transforming growth factor-betas: structure, signaling, and roles in nervous system development and functions. J. Neurochem., 75, 2227-2240.

Brundin, P., Karlsson, J., Emgard, M., Schierle, G.S., Hansson, O., Petersen, A. \& Castilho, R.F. (2000) Improving the survival of grafted dopaminergic neurons: a review over current approaches. Cell Transplant., 9, 179-195.

Byers, M.R., O’Neill, P.C., Nishimura, M.C., Philips, H.S. \& Albers, K.M. (1997) Dependence of dental innervation on NGF: comparison of hetero- and homozygous mice lacking NGF with k14NGF transgenic or hybrid rescued TKO mice. Soc. Neurosci. Abstr., 23, 1704.

Byers, M.R., Wheeler, E.F. \& Bothwell, M. (1992) Altered expression of NGF and P75 NGF-receptor by fibroblasts of injured teeth precedes sensory nerve sprouting. Growth Factors, 6, 41-52.

Carrasco, E. \& Werner, P. (2002) Selective destruction of dopaminergic neurons by low concentrations of 6-OHDA and MPP + : protection by acetylsalicylic acid aspirin. Parkinsonism Relat. Disord., 8, 407-411.

Choi-Lundberg, D. \& Rosenthal, A. (1999) Autotransplantation for Parkinson's disease goes a step further. Neuron, 22, 635-636.

Davies, A.M. (1994a) Neurotrophic factors. Switching neurotrophin dependence. Current Biol., 4, 273-276.

Davies, A.M. (1994b) The role of neurotrophins in the developing nervous system. J. Neurobiol., 25, 1334-1348.

Dunnett, S.B. \& Björklund, A. (1992) Staging and dissection of rat embryos. In Dunnett, S.B. \& Bjorklund, A. (eds), Neural Transplantation, a Practical Approach. Oxford University Press, New York, pp. 1-20.

Engele, J. \& Bohn, M.C. (1991) The neurotrophic effects of fibroblast growth factors on dopaminergic neurons in vitro are mediated by mesencephalic glia. J. Neurosci., 11, 3070-3078.

Engele, J., Rieck, H., Choi-Lundberg, D. \& Bohn, M.C. (1996) Evidence for a novel neurotrophic factor for dopaminergic neurons secreted from mesencephalic glial cell lines. J. Neurosci. Res., 43, 576-586. 
Ernfors, P., Lee, K.F. \& Jaenisch, R. (1994) Mice lacking brain-derived neurotrophic factor develop with sensory deficits. Nature, 368, 147-150.

Espejo, E.F., Montoro, R.J., Armengol, J.A. \& Lopez-Barneo, J. (1998) Cellular and functional recovery of Parkinsonian rats after intrastriatal transplantation of carotid body cell aggregates. Neuron, 20, 197-206.

Farkas, L.M., Dunker, N., Roussa, E., Unsicker, K. \& Krieglstein, K. (2003) Transforming growth factor-beta (s) are essential for the development of midbrain dopaminergic neurons in vitro and in vivo. J. Neurosci., 23, $5178-5186$.

Fried, K., Nosrat, C., Lillesaar, C. \& Hildebrand, C. (2000) Molecular signaling and pulpal nerve development. Crit. Rev. Oral Biol. Med., 11, 318-332.

Gash, D., Zhang, Z., Ovadia, A., Cass, W., Yi, A., Simmerman, L., Russell, D., Martin, D., Lapchak, P., Collins, F., Hoffer, B. \& Gerhardt, G. (1996) Functional recovery in parkinsonian monkeys treated with GDNF. Nature, 380, 252-255.

Granholm, A.C., Henry, S., Hebert, M.A., Eken, S., Gerhardt, G.A. \& Vanhorne, C. (1998) Kidney cografts enhance fiber outgrowth from ventral mesencephalic grafts to the 6-OHDA-lesioned striatum, and improve behavioral recovery. Cell Transplantation, 7, 197-212.

Granholm, A., Srivastava, N., Mott, J., Henry, S., Henry, M., Westphal, H., Pichel, J., Shen, L. \& Hoffer, B.J. (1997) Morphological alterations in the peripheral and central nervous system of mice lacking glial cell line-derived neurotrophic factor (GDNF): Immunohistochemical studies. J. Neurosci., 17, $1168-1178$.

Gronthos, S., Brahim, J., Li, W., Fisher, L.W., Cherman, N., Boyde, A., DenBesten, P., Robey, P.G. \& Shi, S. (2002) Stem cell properties of human dental pulp stem cells. J. Dent. Res., 81, 531-535.

Gronthos, S., Mankani, M., Brahim, J., Robey, P.G. \& Shi, S. (2000) Postnatal human dental pulp stem cells (DPSCs) in vitro and in vivo. Proc. Natl Acad. Sci. USA, 97, 13625-13630.

Hefti, F. (1986) Nerve growth factor promotes survival of septal cholinergic neurons after fimbrial transections. J. Neurosci., 6, 2155-2162.

Henderson, C.E., Phillips, H.S., Pollock, R.A., Davies, A.M., Lemeulle, C., Armanini, M., Simmons, L., Moffet, B., Vandlen, R.A., Simpson, L.C., Koliatsos, V.E. \& Rosenthal, A. (1994) GDNF: a potent survival factor for motoneurons present in peripheral nerve and muscle. Science, 266, 10621064.

Hofstetter, C.P., Schwarz, E.J., Hess, D., Widenfalk, J., El Manira, A., Prockop, D.J. \& Olson, L. (2002) Marrow stromal cells form guiding strands in the injured spinal cord and promote recovery. Proc. Natl Acad. Sci. USA, 99, 2199-2204.

Jones, K.R.I., Backus, C. \& Reichardt, L.F. (1994) Targeted disruption of the BDNF gene perturbs brain and sensory neuron development but not motor neuron development. Cell, 76, 989-999.

Karavanov, A., Sainio, K., Palgi, J., Saarma, M., Saxen, L. \& Sariola, H. (1995) Neurotrophin 3 rescues neuronal precursors from apoptosis and promotes neuronal differentiation in the embryonic metanephric kidney. Proc. Natl Acad. Sci. USA, 92, 11279-11283.

Kruger, G.M., Mosher, J.T., Bixby, S., Joseph, N., Iwashita, T. \& Morrison, S.J. (2002) Neural crest stem cells persist in the adult gut but undergo changes in self-renewal, neuronal subtype potential, and factor responsiveness. Neuron, 35, 657-669.

Lillesaar, C., Eriksson, C. \& Fried, K. (2001) Rat tooth pulp cells elicit neurite growth from trigeminal neurones and express mRNAs for neurotrophic factors in vitro. Neurosci. Lett., 308, 161-164.

Luquin, M.R., Montoro, R.J., Guillen, J., Saldise, L., Insausti, R., Del Rio, J. \& Lopez-Barneo, J. (1999) Recovery of chronic parkinsonian monkeys by autotransplants of carotid body cell aggregates into putamen. Neuron, 22, 743-750.

Luukko, K., Arumae, U., Karavanov, A., Moshnyakov, M., Sainio, K., Sariola, H., Saarma, M. \& Thesleff, I. (1997a) Neurotrophin mRNA expression in the developing tooth suggests multiple roles in innervation and organogenesis. Dev. Dynamics, 210, 117-129.

Luukko, K., Suvanto, P., Saarma, M. \& Thesleff, I. (1997b) Expression of GDNF and its receptors in developing tooth is developmentally regulated and suggests multiple roles in innervation and organogenesis. Devel. Dynam., 210, 463-471.

Matsuo, S., Ichikawa, H., Henderson, T.A., Silos-Santiago, I., Barbacid, M., Arends, J.J. \& Jacquin, M.F. (2001) trkA modulation of developing somatosensory neurons in oro-facial tissues: tooth pulp fibers are absent in trkA knockout mice. Neuroscience, 105, 747-760.

Miura, M., Gronthos, S., Zhao, M., Lu, B., Fisher, L.W., Robey, P.G. \& Shi, S. (2003) SHED: Stem cells from human exfoliated deciduous teeth. Proc. Natl Acad. Sci. USA, 25, 25.
Mohamed, S.S. \& Atkinson, M.E. (1983) A histological study of the innervation of developing mouse teeth. J. Anat., 136, 735-749.

Nosrat, C.A., Fang, M., Kuszpit, K.K. \& Nosrat, I.V. (2002a) Dental pulp cells promote the survival of dopaminergic neurons in vitro. Program No. 635.5.2002. Abstract Viewer/Itinerary planner, Society for Neuroscience, Washington, DC. On line.

Nosrat, C.A., Fried, K., Ebendal, T. \& Olson, L. (1998) NGF, BDNF, NT-3, NT4 and GDNF in tooth development. Eur. J. Oral Sci., 106, 94-99.

Nosrat, C.A., Fried, K., Lindskog, S. \& Olson, L. (1997a) Cellular expression of neurotrophin mRNAs during tooth development. Cell Tissue Res., 290, 569-580.

Nosrat, I., Seiger, A., Olson, L. \& Nosrat, C.A. (2002b) Expression patterns of neurotrophic factor mRNAs in developing human teeth. Cell Tissue Res., 310, $177-187$.

Nosrat, C.A., Tomac, A., Hoffer, B.J. \& Olson, L. (1997b) Cellular and developmental patterns of expression of Ret and GDNFR- $\alpha$ mRNAs. Exp. Brain Res., 115, 410-422.

Nosrat, C.A., Tomac, A., Lindqvist, E., Lindskog, S., Humpel, C., Stromberg, I., Ebendal, T., Hoffer, B.J. \& Olson, L. (1996) Cellular expression of GDNF mRNA suggests multiple functions inside and outside the nervous system. Cell Tiss. Res., 286, 191-207.

Nosrat, I.V., Widenfalk, J., Olson, L. \& Nosrat, C.A. (2001) Dental pulp cells produce neurotrophic factors, interact with trigeminal neurons in vitro and rescue motoneurons after spinal cord injury. Devel. Biol., 238, 120-132.

Olson, L. (1997) Regeneration in the adult central nervous system: experimental repair strategies. Nat. Med., 3, 1329-1335.

Olson, L., Seiger, A. \& Strömberg, I. (1983) Intraocular transplantation in rodents. A detailed account of the procedure and examples of its use in neurobiology with special reference to brain tissue grafting. In Federoff, S. \& Hertz, L. (eds), Advances in Cellular Neurobiology, Vol. 4. Academic, New York, pp. 407-442.

Oppenheim, R.W., Houenou, L.J., Johnson, J.E., Lin, L.F., Li, L., Lo, A.C., Newsome, A.L., Prevette, D.M. \& Wang, S. (1995) Developing motor neurons rescued from programmed and axotomy-induced cell death by GDNF. Nature, 373, 344-346.

Oppenheim, R.W., Yin, Q.W., Prevette, D. \& Yan, Q. (1992) Brain-derived neurotrophic factor rescues developing avian motoneurons from cell death. Nature, 360, 755-757.

Othberg, A.I., Willing, A.E., Cameron, D.F., Anton, A., Saporta, S., Freeman, T.B. \& Sanberg, P.R. (1998) Trophic effect of porcine Sertoli cells on rat and human ventral mesencephalic cells and hNT neurons in vitro. Cell Transplantation, 7, 157-164.

Pichel, J.G., Shen, L.Y., Sheng, H.Z., Granholm, A.C., Drago, J., Grinberg, A., Lee, E.J., Huang, S.P., Saarma, M., Hoffer, B.J., Sariola, H. \& Westphal, H. (1996) Defects in enteric innervation and kidney development in mice lacking GDNF. Nature, 382, 73-76.

Prockop, D.J., Azizi, S.A., Phinney, D.G., Kopen, G.C. \& Schwarz, E.J. (2000) Potential use of marrow stromal cells as therapeutic vectors for diseases of the central nervous system. Prog. Brain Res., 128, 293-297.

Qian, X.B. \& Naftel, J.P. (1994) The effects of anti-nerve growth factor on retrograde labelling of superior cervical ganglion neurones projecting to the molar pulp in the rat. Arch. Oral Biol., 39, 1041-1047.

Qian, X.B. \& Naftel, J.P. (1996) Effects of neonatal exposure to antinerve growth factor on the number and size distribution of trigeminal neurones projecting to the molar dental pulp in rats. Arch. Oral Biol., 41, 359-367.

Ramon-Cueto, A., Plant, G.W., Avila, J. \& Bunge, M.B. (1998) Long-distance axonal regeneration in the transected adult rat spinal cord is promoted by olfactory ensheathing glia transplants. J. Neurosci., 18, 3803-3815.

Rochlin, M.W., O'Connor, R., Giger, R.J., Verhaagen, J. \& Farbman, A.I. (2000) Comparison of neurotrophin and repellent sensitivities of early embryonic geniculate and trigeminal axons. J. Comp. Neurol., 422, 579-593.

Rosenthal, A. (1998) Auto transplants for Parkinson's disease? Neuron, 20, $169-172$.

Sanberg, P.R., Borlongan, C.V., Othberg, A.I., Saporta, S., Freeman, T.B. \& Cameron, D.F. (1997) Testis-derived Sertoli cells have a trophic effect on dopamine neurons and alleviate hemiparkinsonism in rats. Nature Med., $\mathbf{3}$, $1129-1132$.

Sautter, J., Meyer, M., Spenger, C., Seiler, R.W. \& Widmer, H.R. (1998) Effects of combined BDNF and GDNF treatment on cultured dopaminergic midbrain neurons. Neuroreport, 20, 1093-1096.

Sendtner, M., Holtmann, B., Kolbeck, R., Thoenen, H. \& Barde, Y.A. (1992) Brain-derived neurotrophic factor prevents the death of motoneurons in newborn rats after nerve section. Nature, 360, 757-759. 
Skinner, M.K. (1993) Secretion of growth factors and other regulatory factors. In Russell, L.D. \& Griswold, M.D. (Eds), The Sertoli Cell. Cache River Press, Clearwater, FL, pp. 237-248.

Terling, C., Rass, A., Mitsiadis, T.A., Fried, K., Lendahl, U. \& Wroblewski, J. (1995) Expression of the intermediate filament nestin during rodent tooth development. Int. J. Dev. Biol., 39, 947-956.

Toledo-Aral, J.J., Mendez-Ferrer, S., Pardal, R., Echevarria, M. \& LopezBarneo, J. (2003) Trophic restoration of the nigrostriatal dopaminergic pathway in long-term carotid body-grafted parkinsonian rats. J. Neurosci., 23, 141-148.

Toma, J.G., Akhavan, M., Fernandes, K.J., Barnabe-Heider, F., Sadikot, A., Kaplan, D.R. \& Miller, F.D. (2001) Isolation of multipotent adult stem cells from the dermis of mammalian skin. Nat. Cell Biol., 3, 778-784.

Tomac, A., Lindqvist, E., Lin, L.F., Ogren, S.O., Young, D., Hoffer, B.J. \& Olson, L. (1995a) Protection and repair of the nigrostriatal dopaminergic system by GDNF in vivo. Nature, 373, 335-339.

Tomac, A., Widenfalk, J., Lin, L., Kohno, T., Ebendal, T., Hoffer, B. \& Olson, L. (1995b) Retrograde axonal transport of glial cell line-derived neurotrohic factor in the adult nigrostriatal system suggests a trophic role in the adult. Proc. Natl Acad. Sci. USA, 92, 8274-8278.
Unsicker, K. \& Krieglstein, K. (2000) Co-activation of TGF-ss and cytokine signaling pathways are required for neurotrophic functions. Cytokine Growth Factor Rev., 11, 97-102.

de Vicente, J.C., Cabo, R., Ciriaco, E., Laura, R., Naves, F.J., Silos-Santiago, I. \& Vega, J.A. (2002) Impaired dental cytodifferentiation in glial cell-line derived growth factor (GDNF) deficient mice. Ann. Anat, 184, 85-92.

Widenfalk, J., Lundstromer, K., Jubran, M., Brene, S. \& Olson, L. (2001) Neurotrophic factors and receptors in the immature and adult spinal cord after mechanical injury or kainic acid. J. Neurosci., 21, 3457-3475.

Williams, L.R., Varon, S., Peterson, G.M., Wictorin, K., Fischer, W., Björklund, A. \& Gage, F.H. (1986) Continuous infusion of nerve growth factor prevents basal forebrain neuronal death after fimbria fornix transection. Proc. Natl Acad. Sci. USA, 83, 9231-9235.

Yan, Q., Elliott, J. \& Snider, W.D. (1992) Brain-derived neurotrophic factor rescues spinal motor neurons from axotomy-induced cell death. Nature, $\mathbf{3 6 0}$, $753-755$.

Zhang, J., Geula, C., Lu, C., Koziel, H., Hatcher, L.M. \& Roisen, F.J. (2003) Neurotrophins regulate proliferation and survival of two microglial cell lines in vitro. Exp. Neurol., 183, 469-481. 